НЕМЕЗИДА ПРИБЛИЗИЛАСЬ К СОЛНЦУ

\author{
Гусев Анатолий Иванович \\ Д-р геолого-минералогических наук, профессор \\ Алтайский государственный гуманитарно-педагогический \\ университет им. В.М. Шукшина \\ Гусева Ольга Ивановна \\ Член Русского географического общества
}

\title{
NEMESIS APPROXIMATED TO SUN
}

Gusev A.I.

Doctor of geology-mineralogical sciences, professor Shukshin Altai State University for Humanities \& Pedagogy

Guseva O.I.

Member of Russian Geographic Society

\begin{abstract}
Аннотация. Приведены фотографии двойного Солнца, снятые с Проходной Гривы Горного Алтая (вблизи г. Белокурихи). Отмечены доказательства приближения второго Солнца - Немезиды к нашему светилу. Влияние Немезиды на космические события в Солнечной системе весьма впечатляющи, что свидетельствует о взаимодействии двух звёзд и влиянии второго Солнца на планеты Солнечной системы. Наблюдались мощные выбросы плазмы в виде концентрированных лучей со стороны нашего Солнца и отделение крупного сгустка голубого спектра со стороны Немезиды, что указывает на существенно гелиевую составляющую. Сама Немезида может быть отнесена к классу В - бело-голубых гигантов. Аномальные движения магнитных полюсов Земли вызваны воздействием Немезиды могут привести к переполюсовке на Земле.

Abstract. Photographs of double Sun lead in paper that it took off with Prohodnaja Griva of Gornyy Altay (near c. Belokurikha). Evidences of approaching second Sun - Nemesis to our Shine. Influence of Nemesis on the cosmic events in Sun system are very impression that its testify about interaction of two stars and influence second Sun on the planets of Sun system. Powerful emissions of plasma in view concentration rays with side of our Sun and separation blue spectrums clots with Nemesis that it point on the essential helium component. Myself Nemesis can to be carry to class B - whiteblue giants. Anomaly movements of magnet poles of Earth call by impact of Nemesis and can be result to reserve polarity on the Earth.
\end{abstract}

Ключевые слова: двойное Солнце, Немезида, класс В (бело-голубой гигант), аномальные космические события, движение магнитных полюсов.

Key words: double Sun, Nemesis, class B (white-blue giant), anomaly cosmic events, movement of magnetic poles.

\section{Введение}

В последнее время привычные знания мироустройства устаревают на глазах, а старые методы перестают работать, и большая часть человечества пребывает в полной растерянности и неопределённости. Поколебалось и представление о мироздании нашей Солнечной системы, как однозвёздной. Всё больше сведений появляется о втором Солнце. Одним из подтверждений того, что Солнечная система должна иметь второе Солнце - это эллиптические орбиты планет Это говорит о том, что у Солнца должен быть двойник. Известно, что физические двойные звезды по эллипсам вращаются вокруг общего центра масс. Однако, если отсчитывать координаты одной звезды относительно другой, то получится, что звезды движутся друг относительно друга тоже по эллипсам. Большинство учёных считает, что вторым светилом в нашей системе является Немезида.

\section{Немезида и признаки её существования}

Немезидой называют теоретически существующую звезду, которую отнесли к ряду «карликовых звезд». Астрономы называют ее компаньоном Солнца - нашего светила. Теория о существовании Немезиды появилась тогда, когда ученые пытались объяснить внезапные вымирания живых видов на нашей планете. В 1984 году палеонтологами Дэвидом Раупом и Джеком Сепкоски [16] была опубликована статья, в которой утверждалось, что авторами выявлена статистическая периодичность скорости вымирания биологических видов в последние 250 миллионов лет путём использования метода анализа временных рядов. Они исследовали скорость вымирания ископаемых семейств морских позвоночных, беспозвоночных и простейших, выявив 12 массовых вымираний, произошедших в этот временной период. Средний интервал между вымираниями составил 26 миллионов лет. На момент публикации статьи два периода массового вымирания (мел-палеогеновое и эоцен-олигоценовое) 
считались связанными с падением на Землю астероида. Хотя Рауп и Сепкоски не могли определить причину предполагаемой периодичности, они предположили, что она может быть связана с внеземными факторами. Позднее вопросами связи геологических циклов и вымираний в связи с космическим влиянием занимались многие учёные [1,2, 4-6, 8-13,15-19].

Следует отметить, что периодичность смены биот в связи с космическими причинами обосновывали также многие российские (Красилов и др. 1985; Вемарк, Найдин и др. 1998; Баринбаум, Ясаманов, 1999; Изох, 1997 и др.) и зарубежные ученые (Walliser, 1986; Me Laren, Goodfellow, 1990 и др.). Непредсказуемые столкновения Земли с кометами и астероидами, способными спровоцировать сценарий «ядерной зимы», происходят, по мнению некоторых учёных, с периодичностью от 7 до 55 млн. лет. Периодичность 26-31 млн. лет фиксируется геологами как циклы, с которыми связаны эпохи метаморфизма и мантийно-плюмового магматизма на Земле (Шокальский, 2000; Добрецов, 1999, 2001; Чумаков, 2000, 2001).

По мнению теоретиков, Немезида может оказывать определенное губительное влияние на составляющие Солнечной планетарной системы, а точнее - изменять орбиты объектов, расположенных максимально далеко от нашего светила. После визита Немезиды, данные объекты (зачастую планеты) меняют свою траекторию таким образом, что становятся потенциально опасными для Земли - могут на неё упасть.

К слову, за весь период астрономических наблюдений существование Немезиды не смогли доказать, но и опровергнуть тоже не решились.

В 1980-х годах ученые (планетологи и биологи) обратили внимание на пугающую закономерность биологические виды нашей планеты массово вымирают циклически. Между такими биологическими катастрофами проходит не мене 27 млн. лет. А если учесть, что последнее эоцен-олигоценовое вымирание произошло 27 млн лет назад, то, вероятно можно ожидать новое вымирание.

Первым о существовании Немезиды заявил российский академик М.Я. Маров (Пулковская обсерватория). Он отмечал, что наше Солнце тоже двойная звезда, у неё есть спутница - звезда Немезида. Звезда Немезида по его мнению является звездой-карликом примерно девятой звёздной величины, находится на сильно эксцентрической орбите с максимальным удалением от Солнца до 2,5 св. лет. Период вращения Немезиды вокруг Солнца составляет 26 млн. лет. При приближении к Солнцу звезда Немезида сильно возмущает кометное облако, забрасывая кометы внутрь Солнечной системы. Интересно отметить, что период исчезновения некоторых органических видов на Земле составляет примерно 26-31 млн. лет. Следовательно, увеличение запыленности вследствие соударений с кометами может приводить к катастрофам на Земле [1].

О существовании губительной звезды - солнечного компаньона заявил в 1984 году астроном Р. Мюллер. Он являлся сотрудником «Калифорнийского университета». Мюллер объяснил, что провоцировать массовую смерть биологических видов на нашей планете может звезда «красный карлик», которая находится от нас на расстоянии в полтора световых года [14]. В дальнейшем сущность Немезиды постоянно менялась. Ее называли «коричневым карликом», потом «белым карликом», потом просто звездой с крайне малой массой. Предполагалось, что Немезида по массе в несколько раз превосходит планету Юпитер. В любом варианте, она должна излучать тусклое свечение, настолько приглушенное, что заметить его невозможно.

В дальнейших рассуждениях в отношении Немезиды ученые предполагали, что она может влиять на составляющие облака «Оорта», которыми служат разнодисперсные куски льда. Многие из них летают вокруг нашего светила по особым орбитам — «долгопериодическим» и эллиптическим. Когда они подлетают к светилу, начинают плавиться и гореть, из-за чего мы их воспринимаем как кометы.

Если загадочная звезда Немезида с определенной периодичностью проходит через вышеописанное облако, то теоретически она может выталкивать из него дополнительные будущие кометы, которые могут врезаться в землю из-за измененной траектории. Таким образом, Немезида повышает вероятность космических «аварий» с участием нашей Земли, которые для нее могут оказаться губительными.

Астрономы пришли к выводу, что параметры орбиты недавно обнаруженного планетоида Седна свидетельствуют о том, что наше Солнце может быть частью двойной звездной системы. Двойные системы, считавшиеся ранее очень редкими, согласно последним данным, являются обычным явлением в нашей Галактике.

Недавнее открытие доктором Майклом Брауном (Michael Brown) [7] крупного астероида Седны может предоставить первые косвенные физические свидетельства существования загадочной второй звезды - так называемой Немезиды - в Солнечной системе.

Брауном установлено, что Седна вращается по чрезвычайно вытянутой эллиптической орбите, а Уолтер Краттенден выявил, что движение планетоида находится в гравитационном резонансе с движением звездыспутника, теоретические параметры орбиты которой были недавно опубликованы. «Седна просто не может находиться там, где она есть, - полагает Майк Браун. - Нет никакой видимой силы, которая могла бы поместить планетоид на такую орбиту. Седна, несмотря на свою эксцентрическую орбиту, все же не приближается в перигелии достаточно близко к Солнцу, чтобы ощутить его гравитационное воздействие, и не удаляется слишком далеко в афелии, чтобы попасть под влияние других звезд. Очень трудно объяснить такое положение Седны, если, конечно, она не сформировалась именно там, где она сейчас находится». «Мне кажется, - говорит Майк Браун, - что орбита Седны сформировалась на ранних стадиях образования 
Солнечной системы. Звезды галактики тогда находились намного ближе друг к другу. Возможно, эти звезды оказали воздействие на планетоид с внешней стороны его орбиты, а затем удалились на значительное расстояние. Поэтому я считаю Седну реликтом, своего рода «ископаемой окаменелостью», по которой можно изучать самую раннюю историю Солнечной системы». Уолтер Краттенден соглашается с тем, что орбита Седны очень необычна, но отмечает, что орбитальный период в 12 тыс. лет находится в полном соответствии с предполагаемой периодичностью движения звезды-спутника Солнца - Немезиды. Таким образом, по мнению Уолтера Краттендена, необычная орбита Седны отражает текущую конфигурацию Солнечной системы, а не только ее историю и свидетельствует о влиянию на неё Немезиды.

Сама Немизида, разумеется, в пределы Солнечной системы не “залетает” никогда, но периодически (надо понимать, около 26-27 млн лет), “задевает край” этого самого Облака Оорта и воздействует на космические объекты Солнечной системы.

Несмотря на наличие таких телескопов как Hubble, Keppler и других исследователи до сих пор не увидели эту загадочную Немезиду.

\section{Наблюдения и фотографии двойного Солнца с Проходной Гривы}

12 октября 2018 года О.И. Гусевой были сделаны фотоснимки Солнца с Проходной Гривы (к востоку от г. Белокуриха) фотокамерой Samsung Galaxy -A3. В период от 10 часов 30 минут до 16 часов 30 минут было сделано 20 снимков (рис. 2-5).

На первом снимке за Солнцем виден объект, показывающийся из-за Солнца на $3 / 4$ своей величины. На втором снимке объект скрыт полностью Солнцем. На третьем и четвёртом снимках объект вновь появляется и виден примерно на 1/3 своей величины. Если на снимках 1-4 лучи имеют сравнительно небольшую мощность, то на 5 и 6 снимках видны мощные и концентрированные лучи плазмы, указывающие на интенсивный физический обмен между объектами энергией и веществом (рис. 1). На двух последних снимках объект скрыт за Солнцем. При большем увеличении второе Солнце имеет вид бублика с зональным строением: ядерная часть объекта более тёмная и периферическая - более светлая. Иногда во втором Солнце появляется корона голубого спектра. Корона голубого цвета и сам цвет звезды белый характерны согласно Гарвардской классификации для звёзд бело-голубых гигантов (класс В). Их главные характеристики: эффективная температура от 10000 до $30000^{\circ} \mathrm{C} ; 18$ Солнечных масс; 7 Солнечных радиусов; светимость 20 000; линии водорода средние.

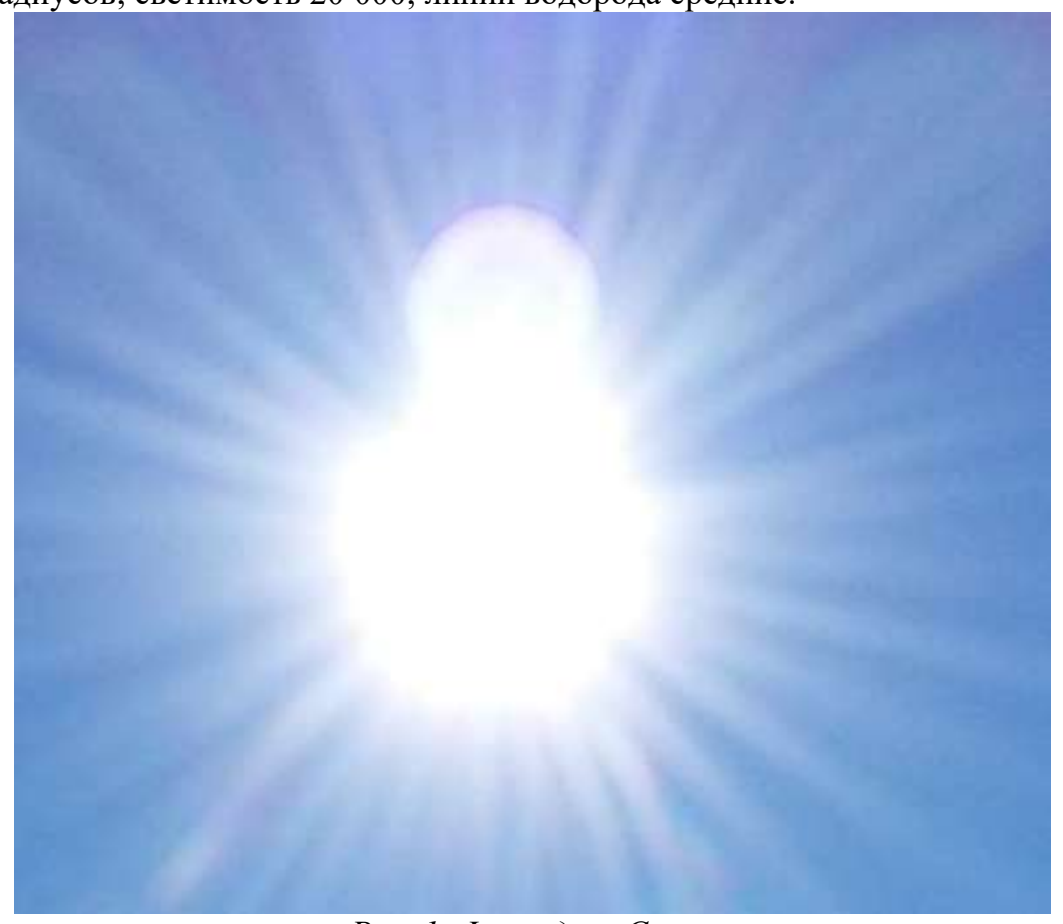

Рис. 1. Фото двух Солни

В нашем случае от второго Солнца неоднократно наблюдалось отделение сгустков голубого цвета, что характерно для существенно гелиевой составляющей.

На следующей серии снимков объект не виден, но наблюдаются мощнейшие лучи видимого спектра излучения (плазмы), в том числе и раздвоенные (рис. 2). Последние наблюдаются при смене направления плазменных лучей. Явно плазменные лучи выбрасывает наше Солнце. Над нашим Солнцем видна голубая корона скрывшейся второй звезды. На снимке видно, что в плазменных лучах выбрасываемых Солнцем видны голубые оттенки за счёт наложения излучения от второй звезды. 


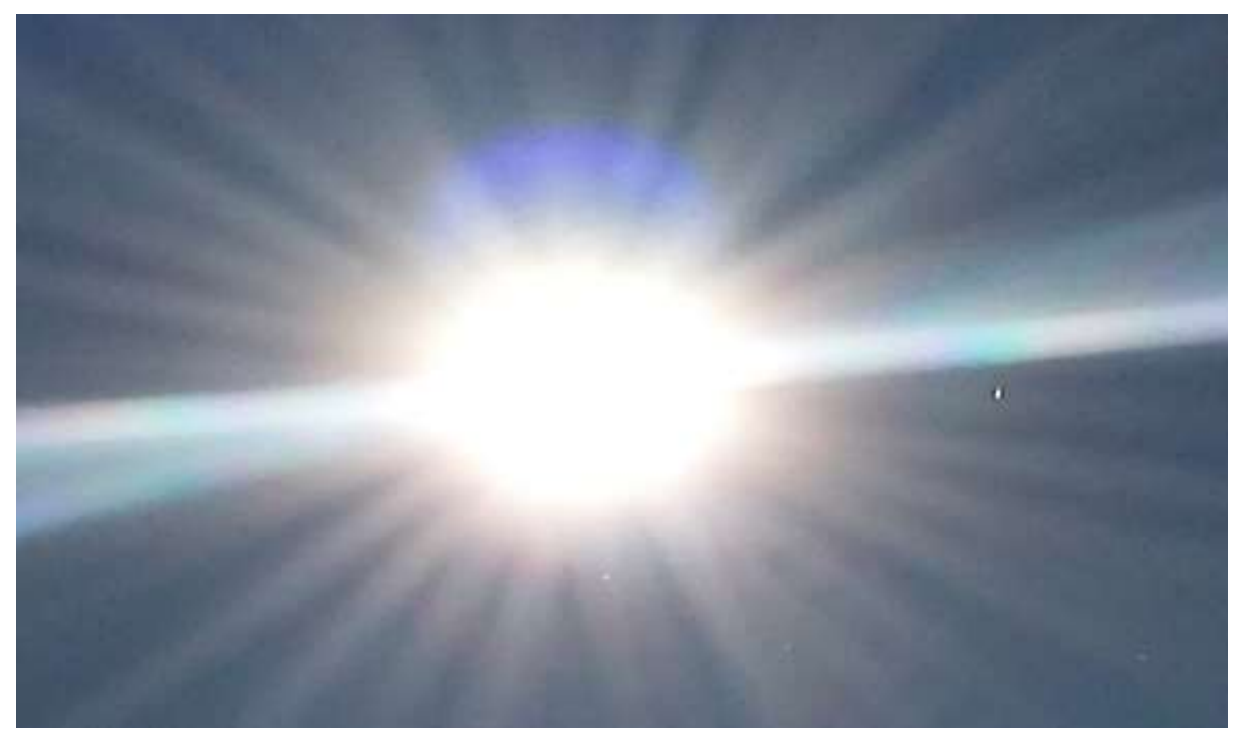

Рис. 2. Синяя корона от скрывшейся Немезиды за Солнцем

На следующих 15 снимках второй объект скрыт за Солнцем, но фиксируется мощные выбросы плазмы. На 20 снимке вновь появляется второй объект, видимый на 3/4 своей величины.

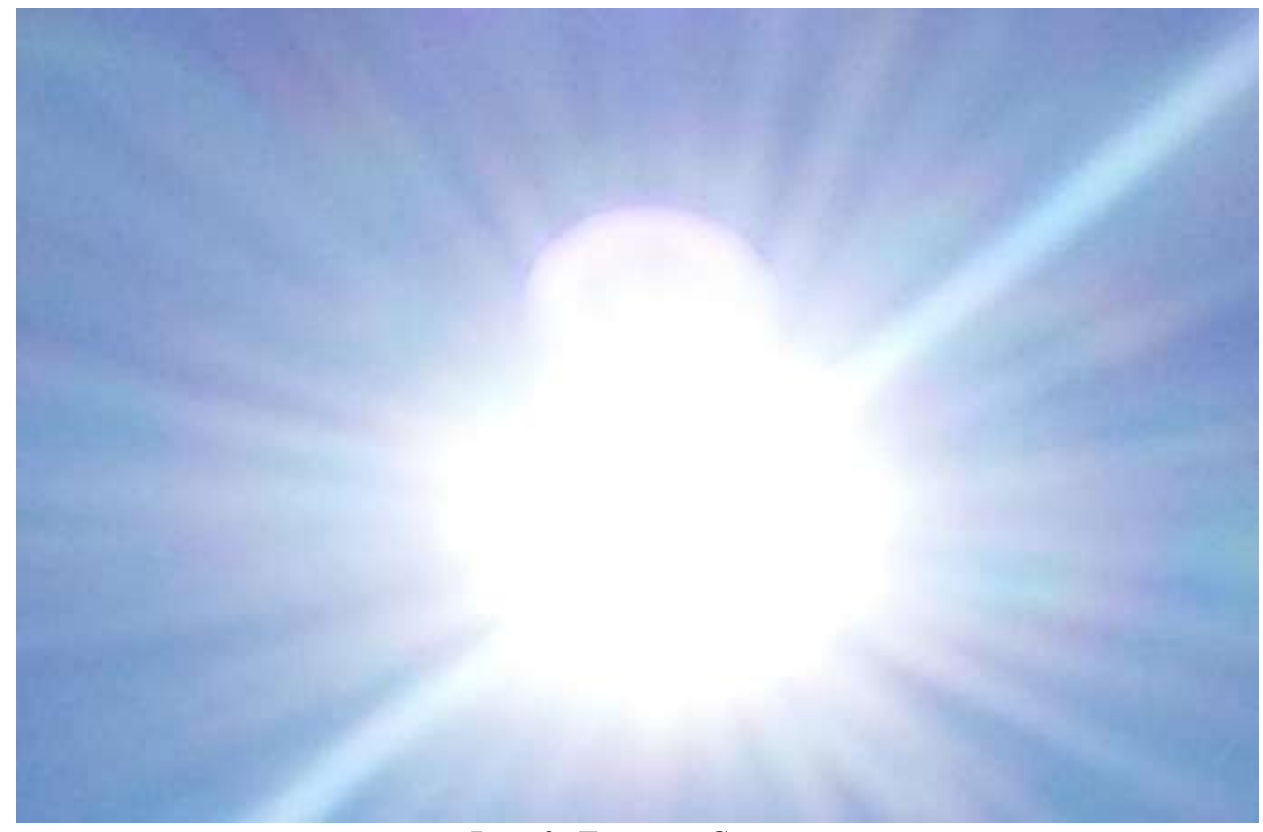

Рис. 3. Двойное Солние

В целом следует определённая закономерность: на первых кадрах происходило совпадение мощного концентрированного излучения плазмы и видимого второго Солнца, а в поздней серии снимков при появлении второй звезды за нашим светилом излучение рассеянное во все стороны, а когда второй объект скрыт за Солнцем проявляются мощные концентрированные лучи выбросов плазмы, которые меняли свою ориентировку на протяжении 5 часов съёмки.

Второе Солнце излучает другой спектр - синий. Когда второе солнце скрывается за нашим светилом, то выше Солнца появляется синяя корона от Немезиды (рис.2).

Нами зафиксирован выброс сгустка голубого спектра от Немезиды на довольно большое расстояние (рис. 4). При этом над Солнцем пропадает голубая корона Немезиды. 


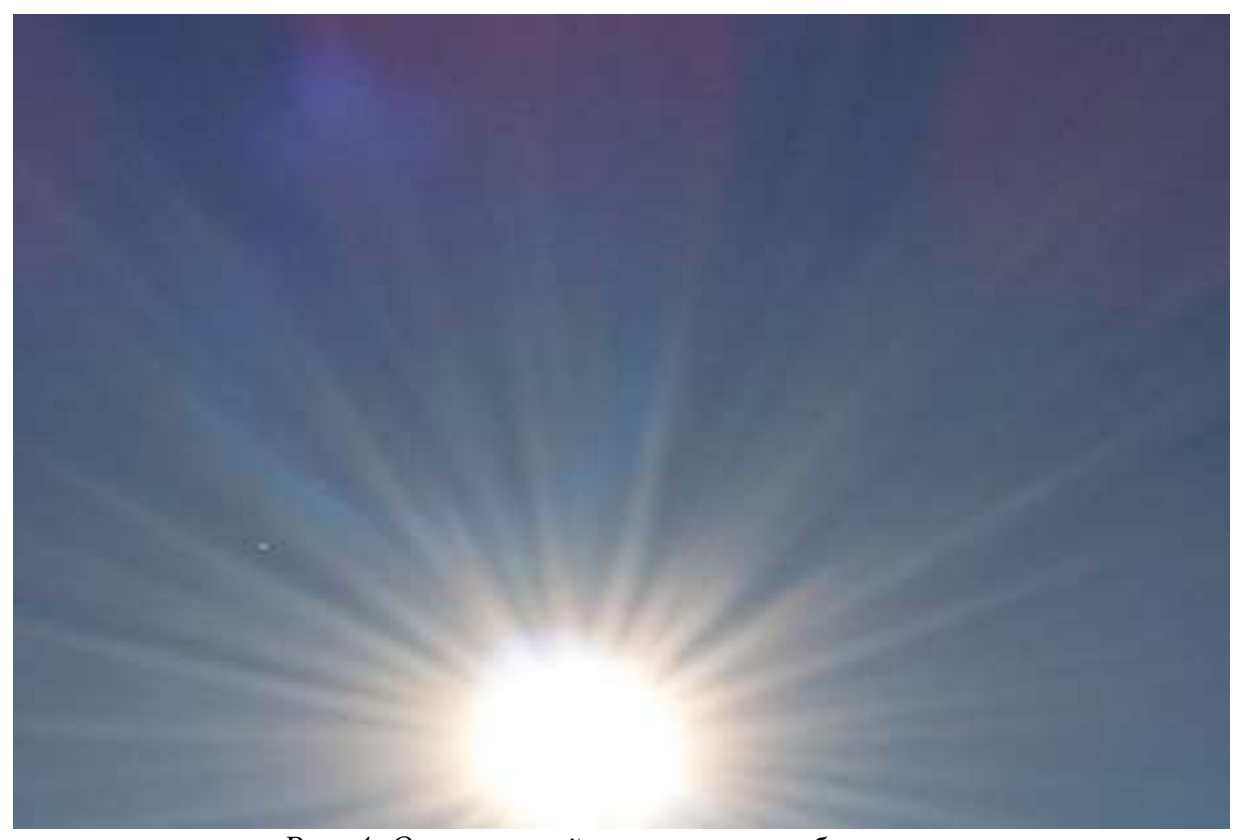

Рис. 4. Оторвавшийся сгусток голубого гелия

Следует отметить, что 12 октября 2018 года Гелиогеофизической службой ФГБУ "ИПГ" на Солнце зарегистрирована вспышка С 3.2 продолжительностью 91 минута.

В Интернете имеется фото солнечной вспышки 12 октября 2018 года, опубликованное Solar Dynaтics Observatory — космической обсерваторией NASA для изучения Солниа.

12 октября в США также заметили двойное Солнце и мощный выброс плазмы [20].

В Китае два Солнца наблюдали трижды: первый раз в марте 2009 года, второй раз 8 января 2011 года и третий раз 14 января того же года.

\section{Аномальные космические явления, вызванные Немезидой}

В связи с тем, что угловая скорость движения Немезиды является относительно низкой, то её приближение к Солнцу может продолжаться долго. А его приближение и влияние на Солнечную систему должно создавать какие-то космические аномалии. Все планеты кроме Земли и Сатурна отреагировали на приближение Немезиды. Вероятно, это приближение началось ещё в 1998 году, когда зонд Галилео зафиксировал аномальные явления на Юпитере, где вначале возникло красное пятно, затем первое, второе и третье белые, а затем их слияние и, в конечном счёте, объединение их и образование двух крупных пятен. Учёные считают, что эта аномалия на Юпитере - результат возникновения вихрей.

В 2001 году в августе Марс из «красной планеты» превратился в жёлтую, а затем вновь в «красную». Жёлтый цвет планеты интерпретируется её встряской в результате «марсотрясения» и поднятием в атмосферу планеты большой массы пыли и песка. Тригерром встряски могла быть приблизившаяся Немезида.

В 2002 году отреагировало Солнце, на котором резко увеличилось количество и размеры гранул. Эта аномалия отнесена астрофизиками к числу невероятных событий в астрономии.

В 2003 году в конце сентября Солнце выбросило в сторону Земли 7 залпов солнечного ветра и плазмы. Магнитосфера Земли отразила 6 атак. 7 залп связан с тем, что от протуберанца Солнечной короны оторвался плазменный болид, который приземлился в районе Тунгуски. В 2003 году в результате выброса плазмы Солнцем вышел из строя спутник NASA.

2 февраля 2014 года засвидетельствовано, что новые измерения с европейского спутника Venus Express показывают 243,023 земных суток, что на 6,5 минуты больше, чем раньше, сообщает Европейское космическое агентство.

4 января 2015 года поступило сообщение, что последние пару лет стало отчетливо прослеживаться нарушение привычной траектории прохождения по небосводу Луны и Солнца, а также не совпадение координат восходов и заходов с расчетными. Констатируется, что Луна сместилась со своей орбиты.

2015 год. Международное время станет на секунду дольше, информирует ТАСС со ссылкой на заявление руководителя главного метрологического центра Государственной службы времени и частоты Игоря Блинова. Событие, которое случится в 3 часа утра 1 июля, связано со снижением скорости вращения Земли.

Солнечным коронографом в начале сентября 2017 года зарегистрирована мощная вспышка на Солнце, а через некоторое время произошло сонцетрясение, затем 10 сентября на обратной стороне светила произошла ещё более мощная вспышка, в результате которой основной удар пришёлся на Венеру. Это были гигантские выбросы плазмы 
со скоростью около 250 тыс км/сек и температурой до 1,5 млн градусов. Для астрономов это было необъяснимое явление, не укладывающееся в 11 летний цикл активности Солнца, максимум которого был зарегистрирован 2012 году. Подобная геомагнитная буря на Солнце произошла в 1859 году, названная бурей Кэррингтона, в результате которой уменьшилось количество озона в атмосфере Земли на 5\%. Для его восстановления потребовалось 4 года. В результате Солнечного супершторма произошёл сбой в работе телеграфа.

20 июля 2018 года в ряде районов севера Якутии, из поля зрения резко исчезло Солнце, вскоре после этого там начали находить множество тушек мертвых птиц.

В октябре 2020 года ученые Юго-западного научно-исследовательского института в США обнаружили яркие ультрафиолетовые вспышки в атмосфере Юпитера, аналогичные спрайтам и эльфам на Земле. Феномен кратковременных световых явлений (TLE, transient luminous events) был зафиксирован с помощью ультрафиолетового спектрографа на борту космического аппарата Juno. Спектрограф выявил 11 кратковременных ярких вспышек длительностью 1,4 миллисекунды. Они произошли в атмосфере газового гиганта на высоте 260 километров над слоем, где давление равно атмосферному давлению на Земле на уровне моря (1 бар). Феномен нельзя объяснить обычными молниями, которые вспыхивают на 300 километров ниже. В спектре вспышек преобладало ультрафиолетовое излучение серии Лаймана, возникающего при переходе электронов с возбужденных энергетических уровней в атоме водорода на первый. На основе этих характеристик астрофизики пришли к выводу, что они наблюдали именно TLE [Giles, 2020].

В 2020 году учёные констатировали, что Центр тяжести Солнечной системы смещается. Как показали астрономические наблюдения, центр масс Солнечной системы находится значительно выше поверхности Солнца: Солнце вокруг этого центра вращается примерно так: ни Юпитер, ни все остальные планеты вместе взятые не могут настолько сместить барицентр Солнечной системы. Такое смещение может быть связано с приближением к Солнцу Немезиды.

23 июня 2020 года было зафиксировано нечто необычное. Земное магнитное поле качнулось назад и вперед примерно на $1 / 3$ градуса. Это необъяснимая аномалия для модели с одной звездой.

На Земле, как планете, также выявлена своеобразная аномалия глобального масштаба, которая обсуждается всем научным сообществом. В связи с аномально-активными процессами на Солнце и в солнечной системе отмечено следующее: недавние парады планет и аномальные перемещения магнитных полюсов Земли. В 2008 году они составляли: северного со скоростью до 15 км в год, южного - 8-9 км в год, в то время как нормальное перемещение при динамически стабильном периоде - смещение магнитных полюсов происходит со скоростью 3 4 см в год. С 2013 года скорость движения магнитных масс Северного магнитного полюса составляет от 55 до 60 км/год. Он движется от Канады в сторону Западной Сибири. Объяснение этого феномена кроется в крупных перемещениях расплавленного вещества в нижней мантии и ядре Земли, а также перемещения вызываются внешними космическими силами. Резко активизировались эндогенные процессы по всему земному шару многочисленные землетрясения, вулканические извержения в Индонезии, и во всём Тихоокеанском регионе (в том числе и в области Охотско-Средиземноморского пояса, куда попадает и территория Горного Алтая). Есть сведения об активизации процессов под Эльбрусом и Йеллоустоном. В конце 2004 года серия катастрофических землетрясений в Японии и Юго-Восточной Азии подтвердили аномальность развития Земли в последнее время. В результате резкой прецессии земной оси произошло катастрофическое землетрясение и моретрясения в ЮгоВосточной Азии, что вызвало смещение крупных плит на 30 метров, что зафиксировано с помощью спутников и сети GPS- геодезии. Это влияние приблизившейся к Солнцу Немезиды. В конечном счёте это может привести к магнитной переполюсовке на Земле.

Изменения произошли не только м мегамире, но и в микромире. С 31 декабря 2012 на 1 января 2013 годы произошёл квантовый переход, который установили ядерщики-физики во многих Лабораториях Мира в атоме водорода. Протон принял новое значение и уменьшился на $4 \%$. В результате этого изменилось всё - его скорость, вращение, направление, диаметр. Трансформировалась вся органика, т.к. она состоит из водорода. Поменялась плотность Материи [21, 22].

В 2019 году экологи подтвердили о начале эпохи современного массового вымирания. На сегодняшний день специалисты по биоразнообразию во главе с Паулем Эрлихом (Paul Ehrlich) уже пришли к выводу, что к XXI веку темпы вымирания достигли уровня, сравнимого с вымиранием динозавров 66 миллионов лет назад. Но если ранее некоторые исследователи высказывали сомнения по этому поводу, то теперь Пауль Эрлих и его коллеги представили крайне убедительные доказательства в пользу этой гипотезы.

Новое исследование, результаты которого изложены в статье журнала Science Advances, показывает, что даже по очень скромным подсчётам, современные виды исчезают примерно в 100 раз быстрее, чем нормальная скорость между массовыми вымираниями - известная как фоновая скорость [23].

\section{ЗАКЛЮЧЕНИЕ}

Уникальные снимки Солнца и второго объекта, попавшего в обзор, указывают на исключительно благоприятное и удачное место съёмки, когда на одной линии и в одной плоскости произошло совмещение нашего светила, второго Солнца и фотокамеры, что может быть тогда, когда наблюдатель окажется в плоскости орбит обеих звёзд. Вторым Солнцем, возможно является Немезида, которая в своей траектории подошла относительно 
довольно близко к Солнцу. При этом второй объект не может быть карликом. Он выглядит весьма крупным объектом, учитывая его далёкое расположение и может быть отнесено к классу $\boldsymbol{B}$ - бело-голубым гигантам. Наблюдались различные физические процессы и взаимодействие нашего светила и Немезиды. Если Солнце выбрасывало плазменные лучи, то от Немезиды отрывались крупные сгустки голубого спектра, характерные для гелия. Следовательно, нашу Солнечную систему можно отнеси к оптически двойным звёздам, так как снимки с Проходной гривы выполнены случайно в момент совмещения плоскостей орбит. Наличие второй звезды в нашей системе крайне необходимо, вероятно, для стабилизации всей системы и циклической профилактики, которая проходит в настоящее время.

\section{Список литературы}

1. Маров М. Я. Планеты Солнечной системы. - М.: Наука, 1981. - 324 с.

2. Назаров В. И. Глава 8. Теллурические гипотезы сопряженной мегаэволюции и смены биот // Эволюция не по Дарвину: Смена эволюционной модели. - М.: КомКнига, 2005. — С. 252-266. - 520 с.

3. Adrian M. L., Richard B.K. "Do periodicities in extinction-with possible astronomical connections-survive a

4. Bailer-Jones C.A.L. The evidence for and against astronomical impacts on climate change and mass extinctions: a review // International Journal of Astrobiology, 2009. - V. 8, No. 3. - P. 213-239.

5. Bond D.P.G., Stephen E. Grasby S.E. On the causes of mass extinctions , // Palaeogeography, Palaeoclimatology, Palaeoecology, 2017. - V. 478. - P. 3-29.

6. Boulila S., Laskar J., Haq B.U., Galbrun B., Hara N.. Long-term cyclicities in Phanerozoic sea-level sedimentary record and their potential drivers // Global and Planetary Change., - 2018. - V. 165. P. $128-136$.

7. Brown M. Sedna and the birth of the solar system // Bulletin of the American Astronomical Society // American Astronomical Society Meeting 205, 2004. - V. 36. - №. 127.04. - P. 1553.

8. Calner M. Silurian global events - at the tipping point of climate change. / Elewa, Ashraf M.T. (Ed.). - Berlin, Heidelberg : Springer, 2008. — Mass Extinction. - C. 21-57.

9. Erlykin A.D., Harper D.A.T., Sloan T., Wolfendale A.W. Mass extinctions over the last 500 myr: an astronomical cause? // Palaeontology. - 2017. - T. 60. - No. 2. - P. 159-167.

10. Giles R.S., Greathouse T.K., Bonfond B., Gladstone G.R., Kammer J.A., Hue V., Grodent D.C., Gérard J.-C., Versteeg M.H. Possible Transient Luminous Events Observed in Jupiter's Upper Atmosphere // Journal of Geophysical Research: Planets. - 2020- V,125. - I.11. - E006659.

11. Hallam A., Wignall P.B. Mass extinctions and sea-level changes // Earth-Science Reviews. — 1999. — V. 48. P. $217-250$.

12. Knoll A.H., Bambach R.K., Payne J.L., Pruss S., Fischer W.W. Paleophysiology and end-Permian mass extinction // Earth and Planetary Science Letters. — 2007. - V. 256. - No. 3-4 (30 April). - P. 295-313.

13. Little C.T.S, Benton M.J. Early Jurassic mass extinction: A global long-term event ] // Geology. — 1995. V. 23. - No. 6. - P. 495- 498.

14. Melott A. Lieberman B.S., Laird C.M., Martin L.D., Medvedev M.V. , Thomas B.C., Cannizo J.K., Gehrels N., Jackman C.H. Did a gamma-ray burst initiate the late Ordovician mass extinction? // International Journal of Astrobiology., - 2004. - V. 3. - No. 1. - P. 55-61.

15. Muller R.A. Measurement of the lunar impact record for the past 3.5 billion years, and implications for the Nemesis theory // Geological Society of America Special Paper, 2002. - V. 356. - P. 659-665.

16. Rampino M. R., Caldeira K. Periodic impact cratering and extinction events over the last 260 million years // Monthly Notices of the Royal Astronomical Society : journal. — Oxford University Press, 2015. — V. 454. - No. 4. — P. $3480-3484$.

16. Raup D.M.; Sepkoski J.J. Periodicity of Extinctions in the Geologic Past // Proceedings of the National Academy of Sciences of the United States of America, 1984. - V. 81, №. 3. - P. 801-805.

17. Rohde R.A., Muller R.A. Cycles in fossil diversity // Nature, - 2005. - V.434. - No. 7030 .P. 208-210.

18. Stanley S.M. Estimates of the magnitudes of major marine mass extinctions in earth history // Proceedings of the National Academy of Sciences, - 2016. - V. 113. - No. 42. - P. E6325-E6334.

19. Walliser O.H. Global Events in the Devonian and Carboniferous. - Berlin : Springer-Verlag, 1996. — Global Events and Event Stratigraphy in the Phanerozoic. - P. 225-250.

20. https://yandex.ru/images/search?text.

21. https:// netsciencenews.blogspot.com.

22. https://otvet.mail.ru/question/78498948.

23. https://www.vesti.ru/nauka/article/1042743.

\section{References}

1. Marov M.Ya. Planety Solnechnoy sistemy. M.: Nauka, 1981. 324 s. (Russia) 
2. Nazarov V.I. Glava 8. Telluricheskie gipotezy soprjazhonnoy megaevolutsii I smeny biot // Evolutsija ne po Darvinu: Smena evolutsionnoy modeli. M.: KomKniga, 2005. pp. 252-266. - 520 s. (Russia)

3.Adrian M. L., Richard B.K. "Do periodicities in extinction-with possible astronomical connections-survive a revision of the geological timescale?". // The Astrophysical Journal. 2013. V. 773 (1). pp. 6.

4.Bailer-Jones C.A.L. The evidence for and against astronomical impacts on climate change and mass extinctions: a review // International Journal of Astrobiology, 2009. V. 8, No. 3. pp. 213-239.

5.Bond D.P.G., Stephen E. Grasby S.E. On the causes of mass extinctions , // Palaeogeography, Palaeoclimatology, Palaeoecology, 2017. V. 478. pp. 3-29.

6. Boulila S., Laskar J., Haq B.U., Galbrun B., Hara N.. Long-term cyclicities in Phanerozoic sea-level sedimentary record and their potential drivers // Global and Planetary Change., 2018. V. 165. pp. 128-136.

7. Brown M. Sedna and the birth of the solar system // Bulletin of the American Astronomical Society // American Astronomical Society Meeting 205, 2004. V. 36. №. 127.04. pp. 1553.

8. Calner M. Silurian global events - at the tipping point of climate change. / Elewa, Ashraf M.T. (Ed.). - Berlin,

9. Erlykin A.D., Harper D.A.T., Sloan T., Wolfendale A.W. Mass extinctions over the last 500 myr: an astronomical cause? // Palaeontology, 2017. T. 60. No. 2. pp. 159-167.

10. Giles R.S., Greathouse T.K., Bonfond B., Gladstone G.R., Kammer J.A., Hue V., Grodent D.C., Gérard J.-C., Versteeg M.H. Possible Transient Luminous Events Observed in Jupiter's Upper Atmosphere // Journal of Geophysical Research: Planets. 2020. V.125. I.11. - E006659.

11. Hallam A., Wignall P.B. Mass extinctions and sea-level changes // Earth-Science Reviews. 1999. V. 48. pp. 217250.

12. Knoll A.H., Bambach R.K., Payne J.L., Pruss S., Fischer W.W. Paleophysiology and end-Permian mass extinction // Earth and Planetary Science Letters, 2007. V. 256. No. 3-4 (30 April). pp. 295-313.

13. Little C.T.S, Benton M.J. Early Jurassic mass extinction: A global long-term event ] // Geology. 1995. V. 23. No. 6. pp. 495- 498.

14. Melott A. Lieberman B.S., Laird C.M., Martin L.D., Medvedev M.V., Thomas B.C., Cannizo J.K., Gehrels N., Jackman C.H. Did a gamma-ray burst initiate the late Ordovician mass extinction? // International Journal of Astrobiology, 2004. V. 3. No. 1. pp. 55-61.

15. Muller R.A. Measurement of the lunar impact record for the past 3.5 billion years, and implications for the Nemesis theory // Geological Society of America Special Paper, 2002. V. 356. pp. 659—665.

16. Rampino M. R., Caldeira K. Periodic impact cratering and extinction events over the last 260 million years // Monthly Notices of the Royal Astronomical Society: journal. Oxford University Press, 2015. V. 454. No. 4. pp. $3480-3484$.

16. Raup D.M.; Sepkoski J.J. Periodicity of Extinctions in the Geologic Past // Proceedings of the National Academy of Sciences of the United States of America, 1984. V. 81. №. 3. pp. 801-805.

17. Rohde R.A., Muller R.A. Cycles in fossil diversity // Nature, 2005. V. 434. No. 7030 . pp. 208-210.

18. Stanley S.M. Estimates of the magnitudes of major marine mass extinctions in earth history // Proceedings of the National Academy of Sciences, 2016. V. 113. No. 42. Pp. E6325-E6334.

19. Walliser O.H. Global Events in the Devonian and Carboniferous. Berlin : Springer-Verlag, 1996. Global Events and Event Stratigraphy in the Phanerozoic. pp. 225-250.

20. https://yandex.ru/images/search?text.

21. https:// netsciencenews.blogspot.com.

22. https://otvet.mail.ru/question/78498948.

23. https://www.vesti.ru/nauka/article/1042743. 